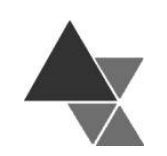

alimentare nutricional

\title{
Desenvolvimento de preparações com adição de pescado e aproveitamento integral de alimentos para a alimentação escolar
}

\author{
Lucinda de Jesus Barros Luz ${ }^{1}$, Fernanda Tavares Silva ${ }^{1}$, Caroline Roberta Freitas Pires ${ }^{1}$, \\ Hellen Christina de Almeida Kato ${ }^{2}$ e Diego Neves de Sousa ${ }^{2}$
}

$\mathrm{Na}$ alimentação escolar existem ainda poucas preparações que utilizam a Carne Mecanicamente Separada (CMS) de pescado e recursos para o aproveitamento integral de alimentos. Diante disso, o objetivo do presente artigo foi elaborar preparações acrescidas de CMS de pescado para serem inseridas na alimentação escolar, juntamente com o aproveitamento integral de alimentos. Foram elaboradas fichas técnicas de preparo das receitas, a fim de se obter informações sobre custo e rendimento das preparações desenvolvidas. A posteriori, foram elaboradas análises diretas, com amostras em triplicata, e indireta, cujos dados obtidos em laboratório foram comparados com aqueles obtidos por meio de tabelas de composição de alimentos disponíveis. Os resultados mostraram que houve divergência entre os indicadores obtidos por meio da análise direta e aqueles da análise indireta, demonstrando também que as preparações desenvolvidas são viáveis do ponto de vista nutricional para serem inseridas na alimentação escolar.

Palavras-chave: Programa Nacional de Alimentação Escolar, peixe, alimentação saudável, aproveitamento integral dos alimentos, composição nutricional.

\section{Development of preparations with addition of fish and integral use of food for school feeding}

In the school feeding there are still few preparations that use the Mechanically Separate Meat (MSM) of fish and the integral use of foods. Therefore, the objective of this article was to elaborate additional MSM preparations of fish along with the integral use of food to be inserted in school feeding. Technical datasheets have been prepared for the preparation of revenues, in order to obtain information on the cost and income of the developed preparations. Rear, direct analyzes were performed with triplicate and indirect samples, in which the data obtained in the laboratory were compared with those obtained through the composite tables. The results showed that there was divergence between the indicators obtained through the direct analysis and those of the indirect analysis, also showing that the developed preparations are nutritionally viable to be inserted in school feeding.

Keywords: National School Feeding Program, fish, healthy food, full use of food, nutritional composition.

${ }^{1}$ Curso de Nutrição - Universidade Federal do Tocantins. Endereço para correspondência: Avenida NS 15, Quadra 109 Norte - Plano Diretor Norte - Palmas - Tocantins - Brasil. CEP: 77001-090.E-mail: carolinerfpires@gmail.com

${ }^{2}$ Embrapa Pesca e Aquicultura - Palmas - Tocantins - Brasil. 


\section{INTRODUÇÃO}

Em termos globais, o Brasil possui considerado volume de recursos hídricos, no qual estima-se que concentre cerca de $12 \%$ da disponibilidade de água doce do planeta ${ }^{[1]}$. Isso torna o país com alto potencial para a piscicultura, pois além de sua vasta disponibilidade hídrica, apresenta também clima favorável e elevada diversidade de espécies aquáticas nativas que compatibilizam interesse zootécnico e mercadológico[].

No ano de 2016, o país teve uma produção de 593,88 mil toneladas de pescado[3]. Em contrapartida, o consumo de pescado vem aumentando anualmente, pois segundo dados divulgados pelo Ministério da Agricultura, Pecuária e Abastecimento (MAPA) o consumo per capita por ano é de $14,4 \mathrm{~kg}$, índice que supera o recomendado pela Organização Mundial da Saúde (OMS) que é de $12 \mathrm{~kg}$ por habitante a cada ano[4].

O pescado é uma fonte proteica importante, tanto quantitativa, quanto qualitativamente. A explicação é que esse alimento apresenta todos os aminoácidos essenciais, com elevado teor em lisina, aminoácido starter do processo digestivo. Contém elevados teores de vitaminas do complexo B, vitaminas $\mathrm{A}, \mathrm{D}$ e tiamina. Quanto aos minerais, a carne de pescado é fonte conhecida principalmente de cálcio e fósforo, mas também de ferro, cobre e selênio, além de iodo, para os peixes de água salgada. Já em relação aos lipídeos, os peixes de água doce apresentam elevados teores de ácidos graxos poliinsaturados, no qual destaca-se a família ômega-3[5,6].

Os ácidos graxos ômega-3 e ômega-6 são considerados fundamentais para o desenvolvimento do sistema nervoso. Além da questão neurológica, observa-se importante papel relacionado à função visual e no desenvolvimento físico e cognitivo infantil, tendo repercussão no cognitivo e na intelectualidade do indivíduo na vida adulta[7]. Sabendo disso, a Nota Técnica no 004/2013[8] fomenta a inclusão do pescado no cardápio da alimentação escolar por meio do Programa Nacional de Alimentação Escolar (PNAE), a fim de propiciar os benefícios supracitados.

O PNAE é responsável por ofertar refeições que cubram as necessidades nutricionais dos escolares durante o período letivo, contribuindo para o crescimento, desenvolvimento biopsicossocial, aprendizagem, rendimento escolar e formação de práticas alimentares saudáveis ${ }^{[?]}$.

A Resolução no 26/2013[9]determina que no mínimo 30\% do valor repassado pelo Fundo Nacional de Desenvolvimento da Educação (FNDE), no âmbito do PNAE, deverão ser utilizados na compra de gêneros alimentícios provenientes da agricultura familiar. Cabe destacar que, conforme a Lei no $11.326 / 2006$, os aquicultores familiares e os pescadores artesanais que cumpram os requisitos estabelecidos na legislação em voga também estão inseridos na categoria dos agricultores familiares, o que viabiliza a oferta do pescado na alimentação escolar ${ }^{[10]}$.

Apesar do inquestionável valor nutritivo do pescado, o seu consumo por crianças em idade escolar ainda é baixo no país, revelando que esse alimento possivelmente não é apreciado pelos escolares ou não é valorizado pelos familiares responsáveis pela aquisição e preparo dos alimentos. Os pais geralmente apresentam grande restrição em fornecer peixe às crianças, sendo o principal motivo o receio de acidentes com a ingestão de espinhas ${ }^{[11]}$.

Uma das alternativas para evitar o risco com as espinhas consiste em utilizar a Carne Mecanicamente Separada (CMS) de pescado, que é o produto obtido de uma única espécie ou de mistura de espécies de peixes com características sensoriais semelhantes. É obtida por processo de separação mecanizada da parte comestível, o que gera partículas de músculo esquelético isentas de vísceras, ossos, pele e espinhas ${ }^{[12]}$. Este subproduto do pescado vem sendo utilizado na alimentação escolar como alternativa, para o preparo de uma refeição em curto espaço de tempo, em pratos como quibe [13], linguiça[14] e biscoitos tipo cookies $^{[15]}$.

Juntamente com a utilização da CMS do pescado na alimentação escolar, pode-se incluir o aproveitamento integral de alimentos, que consiste na utilização máxima das suas partes, sejam estas de origem vegetal ou animal, sobretudo das que comumente são descartadas no preparo das refeições para o consumo humano[16]. Sabe-se que o aproveitamento de partes que normalmente são desprezadas, além de tornar a preparação de baixo custo, ser de fácil acesso e melhorar o valor nutricional, proporciona o aumento do rendimento da 
refeição[17]. Com isso, várias preparações já foram desenvolvidas com o aproveitamento integral na alimentação escolar, comobolos de casca de banana [17] e doces de casca de frutas e suco de laranja com casca e cenoura ${ }^{[18]}$.

Neste contexto, este trabalho teve como objetivo a elaboração e caracterização nutricional de preparações com a adição de CMS de pescado e com o aproveitamento integral dos alimentos no intuito de serem inseridas na alimentação escolar.

\section{MATERIAL E MÉTODOS}

\section{Desenvolvimento das preparações}

Foram desenvolvidas quatro preparações com adição de CMS de pescado e com o aproveitamento integral, sendo estas: arroz cremoso com pescado, cuscuz com pescado, torta de abóbora com pescado e torta de legumes com pescado.
A escolha das receitas foi feita levando-se em consideração os seguintes critérios: fácil preparo, saudabilidade, adaptação ao cardápio local dos escolares, baixo custo e características sensoriais agradáveis nos aspectos aparência, aroma, cor, sabor e textura.

Para a elaboração das preparações, os laboratórios de Técnica Dietética e Tecnologia de Alimentos da Universidade Federal do Tocantins (UFT) foram utilizados. Os ingredientes foram obtidos no comércio local do município de Palmas (Tocantins), com exceção da CMS de pescado, que foi cedido pela Empresa Brasileira de Pesquisa Agropecuária (EMBRAPA).

$\mathrm{Na}$ Tabela 1 é possível observar os ingredientes (e suas respectivas quantidades) utilizados em cada uma das preparações supracitadas.

Tabela 1. Ingredientes e quantidades utilizados nas preparações

\begin{tabular}{|c|c|c|c|c|}
\hline \multirow[b]{2}{*}{ Ingredientes $(\mathrm{g} / \mathrm{ml})$} & \multicolumn{4}{|c|}{ Preparações } \\
\hline & $\begin{array}{l}\text { Arroz com } \\
\text { pescado }\end{array}$ & $\begin{array}{l}\text { Cuscuz com } \\
\text { pescado }\end{array}$ & $\begin{array}{c}\text { Torta de } \\
\text { abóbora com } \\
\text { pescado }\end{array}$ & $\begin{array}{c}\text { Torta de legumes } \\
\text { com pescado }\end{array}$ \\
\hline Abóbora cabotian com casca & - & - & 349 & - \\
\hline Abobrinha com casca & 84 & - & - & 128 \\
\hline Alho & 6 & 12 & 4 & - \\
\hline Arroz branco & 159 & - & - & - \\
\hline Cascas de chuchu & - & 30 & - & - \\
\hline Cebola & 55 & 55 & 118 & 61 \\
\hline Cebolinha & - & - & - & 13 \\
\hline Cenoura com casca & 50 & 111 & - & 102 \\
\hline Chuchu com casca & 60 & - & - & - \\
\hline CMS de pescado & 65 & 150 & 200 & 100 \\
\hline Coentro & - & - & - & 4 \\
\hline Farinha de milho em flocos & - & 250 & - & - \\
\hline Farinha de Trigo & - & - & 235 & 206 \\
\hline Fermento & - & - & 18 & 16 \\
\hline Inhame & 85 & - & - & - \\
\hline Leite integral & 400 & - & 202 & 400 \\
\hline Margarina & - & - & 16 & 54 \\
\hline Óleo & 10 & 8 & 100 & - \\
\hline Ovo & - & - & 91 & 180 \\
\hline Sal & 10 & 9 & 6 & 10 \\
\hline Suco de limão & 13 & 13 & 23 & - \\
\hline Talos de couve & - & 36 & - & - \\
\hline Tomate & - & 225 & 256 & - \\
\hline
\end{tabular}

\footnotetext{
Fonte: Dados da pesquisa.
} 
Para a obtenção dos dados como o custo total da preparação, custo unitário, rendimento, quantidade dos ingredientes e fatores de correção e cocção, foram elaboradas Fichas Técnicas de Preparo (FTP) das receitas. Para isso, utilizou-se uma balança comercial (Marte AD3300, Campinas - SP), com capacidade de 3200g, para a pesagem dos alimentos. Para a caracterização nutricional das preparações, cada receita foi desenvolvida em três repetições, retirando-se 200 gramas de cada preparação para a realização das análises nutricionais.

\section{Determinação da composição centesimal (análise direta)}

Para as determinações de umidade, extrato etéreo, proteínas e cinzas utilizaram se os procedimentos descritos pela Association of Official Analytical Chemists (AOAC) ${ }^{[19]}$, sendo as análises realizadas em triplicata.

$\mathrm{Na}$ determinação de umidade, utilizou-se o método gravimétrico com secagem em estufa a 105 ${ }^{\circ} \mathrm{C}$, até que as amostras estabelecessem peso constante. $\mathrm{O}$ teor de extrato etéreo foi determinado utilizando solvente orgânico (hexano), no qual houve extração em aparelho do tipo Soxhlet. A proteína foi obtida através do método de Kjeldahl, aplicando o fator de conversão 6,25. As cinzas foram determinadas a partir de incineração em mufla a $550^{\circ} \mathrm{C}$. Para a determinação do teor de fibra bruta, utilizou-se o procedimento descrito por Kamer e Ginkel[20], no qual aplicou-se o método gravimétrico após digestão em meio ácido. Os carboidratos totais, ou fração glicídica, foram calculados por diferença, no qual se considerou a matéria integral.

\section{Determinação do valor calórico total (VCT)}

O valor calórico total das preparações foi obtido através da multiplicação da quantidade de cada macronutriente pelo seu devido fator de conversão, que segundo a Agência Nacional de Vigilância
Sanitária ${ }^{[21]}$ os parâmetros são $4 \mathrm{kcal} / \mathrm{g}$ para carboidratos e proteínas, e $9 \mathrm{kcal} / \mathrm{g}$ para lipídeos.

\section{Determinação do valor nutricional (análise indireta)}

Para a determinação do valor nutricional das preparações, utilizou-se a Tabela de Composição Química dos Alimentos (FRANCO) [22], Tabela Brasileira de Composição de Alimentos (TACO) [23], e a Tabela de Composição Nutricional dos Alimentos Consumidos no Brasil (IBGE) [24], por serem as principais referências nacionais sobre composição de alimentos $[25]$.

Os itens que não foram encontrados nessas tabelas foram substituídos por outros semelhantes, de acordo com a orientação de cada tabela. Foram obtidas as informações de valor energético total, carboidratos, proteínas e lipídeos. Para estas determinações foram considerados os valores dos alimentos crus, uma vez que os dados apresentados em tabelas de composição referem-se, em geral, ao alimento in natura[25].

\section{Comparação dos dados obtidos com as Tabelas de Composição de Alimentos (TCA)}

Os dados obtidos a partir da análise direta foram comparados com aqueles obtidos por meio das tabelas de composição de alimentos utilizadas: FRANCO[2], TACO ${ }^{[23]}$ e IBGE[24] por estimativa de diferença[25].

\section{RESULTADOS E DISCUSSÃO}

\section{Custo das preparações}

No Quadro 1, encontram-se os valores da porção e do custo de cada uma das preparações, os quais foram obtidos através das FTP. 
Desenvolvimento de preparações para a alimentação escolar. Luz et al.

Quadro 1. Custo das preparações com adição de pescado e aproveitamento integral de alimentos

\begin{tabular}{|c|c|c|c|c|}
\hline Preparações & $\begin{array}{c}\text { Arroz com pescado } \\
\mathbf{( 2 0 0 g )}\end{array}$ & $\begin{array}{c}\text { Cuscuz com } \\
\text { pescado (200g) }\end{array}$ & $\begin{array}{c}\text { Torta de abóbora } \\
\text { com pescado (120g) }\end{array}$ & $\begin{array}{c}\text { Torta de legumes } \\
\text { com pescado (120g) }\end{array}$ \\
\hline Custo (R\$) & 0,74 & 0,70 & 0,71 & 0,69 \\
\hline
\end{tabular}

Fonte: Dados da pesquisa

De acordo com o Quadro 1 é possível observar que os valores das preparações ficaram compreendidos entre $R \$ 0,69$ e $R \$ 0,74$ centavos por porção.

Conforme orienta a Resolução no 1 , de 8 de fevereiro de 2017, o valor per capita atualmente repassado aos alunos matriculados no ensino fundamental e médio em escolas de tempo parcial é de $\mathrm{R} \$ 0,36[26$, que é referente a apenas ao valor de uma única refeição diárial[9. Diante disso, verifica-se que todas as preparações apresentaram valores superiores ao repassado pelo órgão financiador do PNAE. Contudo, é importante destacar que, na composição dos valores repassados para a alimentação escolar a maior parcela do valor total deve ser proveniente dos recursos dos municípios, como complementação à verba repassada pelo FNDE[2].

Com as alterações na legislação do PNAE registradas a partir de 2009, é necessário que no mínimo $30 \%$ do valor repassado às escolas seja utilizado na aquisição de alimentos diretamente da agricultura familiar e de seus empreendimentos coletivos. Com isso, alimentos utilizados nas receitas como abóbora, abobrinha, cenoura, chuchu, entre outros, podem ser adquiridospelas escolas diretamente dos agricultores familiares, o que contribui para redução no valor total das preparações, assim como na aquisição de alimentos mais saudáveis(in natura) e também na geração de renda e na dinamização do desenvolvimento regional.

Vale ressaltar que para calcular os valores das porções de cada preparação, foram utilizados os preços das matérias-primas e ingredientes adquiridas no varejo, o que aumenta os custos em relação ao que fosse comprado no atacado. Como no PNAE os alimentos são obtidos tanto no varejo como no atacado, por meio de licitação[9], os valores destes tornam-se mais acessíveis, contribuindo também para a redução dos custos.

Contudo, os valores per capita repassados à alimentação escolar ainda são considerados baixos, o que para Bezerra[28] é uma quantia irrisória, já que o repasse de recursos é realizado com base no censo escolar do ano anterior, não levando em consideração o aumento no número de matrículas ${ }^{[9]}$.

Como consequência deste baixo valor repassado às escolas pelo FNDE, ocorre frequentemente a escolha por produtos de menor custo[ ${ }^{[28}$, levando a uma monotonia da dieta, uma vez que fica difícil oferecer o mínimo, sob o ponto de vista da nutrição para os alunos, e os cardápios acabam ficando muito restritos e pobres em nutrientes ${ }^{[2]}$.

A oferta de uma alimentação saudável e adequada, compreende o uso de alimentos variados e seguros, de acordo com as referências nutricionais ${ }^{[9]}$. Para tanto, é necessário que haja um repasse maior de recursos financeiros destinados à alimentação escolar ${ }^{[29]}$.

\section{Atendimento das necessidades nutricionais}

As preparações do presente estudo foram desenvolvidas com $\mathrm{O}$ intuito de atender as necessidades nutricionais mínimas determinadas pelo Programa Nacional de Alimentação Escolar de alunos matriculados no ensino fundamental com idade entre 06 e 10 anos inseridos em escolas que apresentam modalidade de tempo parcial como apresentado no Quadro 2, segundo a Resolução 26/2013[9]. 
Quadro 2.Valores de referência de energia e macronutrientes

\begin{tabular}{|c|c|c|c|c|c|}
\hline \multicolumn{7}{|c|}{ Para atendimento de 20\% das necessidades diárias } \\
\hline Categoria & Idade & Energia (kcal) & $\begin{array}{c}\text { Carboidratos } \\
(\mathbf{g})\end{array}$ & $\begin{array}{c}\text { Proteína } \\
(\mathbf{g})\end{array}$ & $\begin{array}{c}\text { Lipídeos } \\
(\mathbf{g})\end{array}$ \\
\hline $\begin{array}{c}\text { Ensino } \\
\text { Fundamental }\end{array}$ & $6-10$ anos & 300 & 48,8 & 9,4 & 7,5 \\
\hline
\end{tabular}

As porções estabelecidas das preparações desenvolvidas com CMS de pescado e o aproveitamento integral dos alimentos não atingiram a recomendação energética e proteica propostas pelo PNAE. No entanto, os valores energéticos da maioria das preparações ficaram bem próximos do recomendado (Tabela 3). Deste modo, faz-se necessário a complementação com outros alimentos, como frutas ou bebidas naturais (sucos ou vitaminas) para que sejam atendidas as necessidades nutricionais dos alunos.

Para as porções das tortas de legumes e de abóbora com pescado foi estabelecida uma porção de $120 \mathrm{~g}$, o que constitui uma fatia grande de torta. A primeira tem 123,52 kcal e a segunda 289,75 kcal. Embora as tortas não sejam frequentemente inseridas na alimentação escolar, é importante destacar que a alimentação oferecida nas escolas deve ser adequada aos hábitos alimentares e tradições culturais regionais dos alunos, sendo elaboradas preparações saborosas e atrativas ${ }^{[30]}$. Já o arroz cremoso com pescado e o cuscuz com pescado tiveram um valor calórico de $230,46 \mathrm{kcal}$ e $255,06 \mathrm{kcal}$, respectivamente. $\mathrm{O}$ arroz e o cuscuz fazem parte comumente dos cardápios do PNAE, sendo utilizados em diversas preparações ${ }^{31]}$.

Em relação à quantidade proteica das porções, embora nenhuma delas tenha atingido a recomendação preconizada pelo PNAE, destaca-se que a inserção da CMS de pescado nas receitas juntamente com o aproveitamento integral dos alimentos possivelmente contribuíram para o aumento do valor proteico das preparações. Vieira et al.[17] ao elaborarem bolos de banana destinados à alimentação escolar, no qual um deles utilizava somente a polpa da banana e o outro utilizava a polpa e a casca, verificaram, através da composição química realizada em laboratório, que oprimeiro apresentou um teor proteico de 4,93g e o segundo 6,66g. Em outro estudo sobre a elaboração de receitas contendo cascas, folhas, talos e sementes de frutas e vegetais, foi constatado teor proteico variando de $0,3 \mathrm{~g}$ a $12,7 \mathrm{~g}^{[32]}$. Com efeito, a inclusão do pescado juntamente com o aproveitamento integral de alimentos servem para aumentar os teores proteicos e melhorar o valor nutricional de algumas preparações [15,32].

Quanto aos teores de carboidratos e lipídeos somente as preparações de cuscuz com pescado e torta de abóbora com pescado atingiram a recomendação necessária para estes macronutrientes, respectivamente.

\section{Composição química das preparações}

Na Tabela 3 é possível observar o resultado da composição química das preparações através das análises direta e indireta. 
Tabela 3. Composição centesimal (por porção) das preparações

\begin{tabular}{|c|c|c|c|c|}
\hline Tabelas e Amostra & Energia (kcal) & Carboidratos (g) & Proteínas (g) & Lipídeos (g) \\
\hline \multicolumn{5}{|c|}{ Arroz cremoso com pescado (200g) } \\
\hline FRANCO & $255(+10,65 \%)$ & $40,03(-14,44 \%)$ & $9,90(+35,24 \%)$ & $5,55(+290,84 \%)$ \\
\hline TACO & $259,31(+12,52 \%)$ & $41,66(-11,55 \%)$ & $9,60(+31,15 \%)$ & $6,00(+322,53 \%)$ \\
\hline IBGE & $179,29(-22,20 \%)$ & $23,05(-51,06 \%)$ & $8,41(+14,89 \%)$ & $6,06(+326,76 \%)$ \\
\hline AMOSTRA & 230,46 & 47,1 & 7,32 & 1,42 \\
\hline \multicolumn{5}{|c|}{ Cuscuz com pescado (200 g) } \\
\hline FRANCO & $254,2(-0,34 \%)$ & $44,6(-14,46 \%)$ & $11,47(+29,16)$ & $2,73\left(+106,82^{\%} \%\right)$ \\
\hline TACO & $245,78(-3,64 \%)$ & $45,19(-13,33 \%)$ & $10,71(+20,68 \%)$ & $3,21(+143,18 \%)$ \\
\hline IBGE & $255(-0,02 \%)$ & $46,39(-11,03 \%)$ & $11,99(+35,02 \%)$ & $3,04(+130,30 \%)$ \\
\hline AMOSTRA & 255,06 & 52,14 & 8,88 & 1,32 \\
\hline \multicolumn{5}{|c|}{ Torta de abóbora com pescado (120 g) } \\
\hline FRANCO & $324,7(+12,06 \%)$ & $30,7(-8,30 \%)$ & $11,3(+25,69 \%)$ & $17,60(+32,13 \%)$ \\
\hline TACO & $317,68(+9,64 \%)$ & $30,80(-8,00 \%)$ & $11,03(+22,69 \%)$ & $17,25(+29,50 \%)$ \\
\hline IBGE & $316,55(+9,25 \%)$ & $21,65(-35,33 \%)$ & $15,64(+73,97 \%)$ & $19,88(+49,25 \%)$ \\
\hline AMOSTRA & 289,75 & 33,48 & 8,99 & 13,32 \\
\hline \multicolumn{5}{|c|}{ Torta de legumes com pescado (120 g) } \\
\hline FRANCO & $228,94(+85,35 \%)$ & $22,83(+148,15 \%)$ & $9,44(+27,74 \%)$ & $11,03(+73,70 \%)$ \\
\hline TACO & $216,23(+75,06 \%)$ & $23,62(+156,74 \%)$ & $9,24(+25,03 \%)$ & $9,52(+49,92 \%)$ \\
\hline IBGE & $227,26(+83,99 \%)$ & $17,18(+86,74 \%)$ & $12,87(+74,15 \%)$ & $12,70(+100 \%)$ \\
\hline AMOSTRA & 123,52 & 9,20 & 7,39 & 6,35 \\
\hline
\end{tabular}

Fonte: FRANCO (2007), NEPA (2011), IBGE (2011). Os valores entre parênteses correspondem à diferença percentual em relação ao valor da amostra

\section{Composição química obtida através da análise direta}

A partir dos resultadosda análise direta das preparações, observa-se que a amostra de cuscuz com pescado foi a que apresentou menor teor lipídico dentre as quatro receitas, sendo este de $1,32 \mathrm{~g}$ por porção,o que pode ser explicado pela menor adição de óleo de soja nesta formulação (Tabela 1), quando comparada às demais. Além disso, não foi utilizada margarina nesta preparação, contribuindo deste modo para um baixo valor em lipídeos. Já a torta de abóbora com pescado apresentou o maior teor de lipídeos dentre todas as preparações, com 13,32g por porção, pois nesta receita utilizou-se a maior quantidade de óleo de soja dentre as demais. A adição da margarina também colabora para o aumento nos valores de lipídeos totais.

A torta de abóbora com pescado também obteve o maior teor proteico, referente a $8,99 \mathrm{~g}$ por porção, seguida da amostra de cuscuz com pescado com 8,88 g por porção, enquanto o arroz com pescado apresentou o menor teor proteico com $7,32 \mathrm{~g}$ por porção.
O alto valor proteico da receita de torta de abóbora justifica-se pelo motivo desta utilizar a maior quantidade de CMS de pescado em relação às demais receitas, pois os produtos provenientes do pescado são excelentes fontes de proteínas ${ }^{[3]}$.

Veit et al.[11] desenvolveram bolos acrescidos de filé de tilápia do Nilo e compararam com aqueles sem a sua adição, no qual verificaram maior teor proteico daqueles acrescidos de pescado. No ano seguinte, em outro estudo sobre elaboração de formulações de patê com CMS de Matrinxã (Bryconamazonicus) obteve-se percentuais proteicos de $10,35 \%, 10,79 \%$ e $10,40 \%$ para as preparações com $100 \%$ peixe cozido, $70-30 \%$ peixe cru, e $60-40 \%$ peixe cru e cozido, respectivamente, evidenciando este produto à base de pescado como uma rica fonte

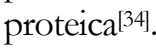

O baixo valor proteico do arroz cremoso com pescado ocorreu devido a esta receita apresentar uma adição de CMS de pescado inferior às demais. Justifica-se que ao se trabalhar com diferentes concentrações de pescado nas preparações, aquela que apresentar menor acréscimo deste ingrediente 
evidencia menor percentual proteico, como foi notado em outra investigação ${ }^{[13]}$, que trabalhou com a elaboração de quibes com diferentes percentuais de CMS de tilápia e linhaça, que constatou maiores valores proteicos na preparação contendo maior porcentagem de CMS e vice-versa. Os percentuais de proteína obtidos das formulações foram de 14,19\% para a preparação em que se utilizou $40 \%$ de CMS e $10 \%$ de linhaça; $11,78 \%$ naquela adicionada de $35 \%$ de CMS e $15 \%$ de linhaça e $10,57 \%$ para aquela inserida com 30\% de CMS e 15\% de linhaça.

Em relação aos teores de carboidratos, as amostras de cuscuz com pescado e arroz com pescado apresentaram os maiores valores, sendo 52,14g e 47,1g por porção, respectivamente. Já a amostra de torta de legumes com pescado apresentou o menor valor, averiguando 9,20g por porção. Esse baixo valor glicídico na última amostra pode estar associado a uma maior quantidade de fibras nesta preparação, pois ao realizar a análise direta, a porção de fibras não é contabilizada juntamente com afração glicídica, o que pode ocasionar déficit nos valores de carboidratos totais.

Estudo realizado por SOUZA et al.[35] envolveu a elaboração de duas tortas salgadas com a inserção do aproveitamento integral de alimentos, como cascas de beterraba e cenoura, além de talos de brócolis e couve-flor, dentre outros ingredientes. Os autores encontraram em $100 \mathrm{~g}$ de cascas de cenoura, o valor de $1,0 \mathrm{~g}$ de fibras e teor bem menor de carboidratos nestas, uma vez que são consideradas boas fontes de fibras. Ainda de acordo com os referidos autores foi identificado menor teor de carboidratos na torta em que foram utilizados mais $(50 \%)$ de talos e cascas em comparação com aquela quese utilizou 50\% menos destes ingredientes, sendo seus valores, em uma porção de $100 \mathrm{~g}, 29,9 \mathrm{~g}$ e $36,9 \mathrm{~g}$, respectivamente. No presente estudo utilizou-se na torta de legumes com pescado a quantidade de $102 \mathrm{~g}$ de cenoura com casca e $128 \mathrm{~g}$ de abobrinha com casca (Tabela 1), o que contribuiu para o aumento da quantidade de fibra bruta e numa diminuição da fração glicídica.

Storck et al. [32] ao realizarem analises envolvendo a composição centesimalde folhas, talos, cascas e sementes de alguns vegetais, encontraram um baixo teor de carboidratos na maior parte desses ingredientes. Já em outro estudo sobre a composição centesimal de cascas de frutas, verificou-se que em sete das amostras analisadas, cinco delas apresentaram teor de fibras maior nas cascas do que na parte comestível, assim como também cinco das amostras apresentaram uma fração de carboidratos inferior nas cascas quando comparadas à parte comestível[36].

Com relação ao valor energético total, ressalta-se que a torta de abóbora com pescado apresentou o maior valor calórico. Este fato pode ser atribuído à concentração lipídica, que repercute na elevação do valor calórico, visto que os lipídeos apresentam mais do que o dobro das calorias que carboidratos e proteínas em apenas $1 \mathrm{~g}^{[21]}$.

\section{Composição química obtida por meio da estimativa das tabelas de composição de alimentos}

Quanto ao teores de macronutrientes obtidos por meio da análise indireta, observa-se que a preparação que apresentou maior teor de lipídeos foi a torta de abóbora com pescado, pela tabela IBGE[24], com 19,88g por porção servida. Em relação à proteína, observa-se que as receitas de torta de abóbora com pescado e torta de legumes com pescado apresentaram os maiores valores pela tabela IBGE[24], sendo estes de $15,64 \mathrm{~g}$ e 12,87g, respectivamente, por porção servida.

$O$ alto teor de lipídeos apresentado na formulação de torta de abóbora com pescado pela tabela de composição IBGE[24], demonstra que esta ferramenta pode contribuir para a variação dos valores de lipídeos dos alimentos, pois um estudo ${ }^{[37]}$ para determinar a composição centesimal e o valor calórico de pratos salgados tradicionais do Rio Grande do Sul, comparando os dados laboratoriais obtidos com aqueles apresentados em Tabelas de Composição de Alimentos, observaram que a tabela IBGE[24] revelou teor lipídico superior das preparações analisadas em relação aos demais valores disponíveis nas outras tabelas utilizadas (TACO e FRANCO).

Os valores proteicos foram elevados quando foi adotada a tabela IBGE[24] porque não foi utilizado o mesmo tipo de pescado das outras tabelas de composição, pois o mesmo não foi encontrado nesta tabela, sendo então substituído por outra espécie de peixe para a realização da composição química. A dificuldade gerada pela falta de ingredientes nas tabelas 
de composição também foi relatada por outros autores ${ }^{[37,38] \text {. }}$

A fração de carboidratos apresentou menor valor na preparação de torta de legumes com pescado, por meio da tabela IBGE[24], sendo este de 17,18g por porção servida. Isso se deve ao fato de que nesta tabela não foi encontrada a farinha de trigo. Por sua vez, este ingrediente foi substituído pelo gérmen de trigo para que pudesse fazer o cálculo da composição nutricional, pois o gérmen de trigo apresenta quantidade menor de carboidratos e maior de fibras quando comparado à farinha de trigo ${ }^{[39]}$.

O valor calórico apresentou-se elevado em duas preparações: torta de abóbora e torta de cuscuz com pescado, analisadas pela tabela FRANCO[22]. Em contrapartida, Ribeiro et al. [40], encontraram valores de energia 55\% menores por meio desta tabela em comparação com os dados laboratoriais.

\section{Comparação entre dados da análise direta e indireta}

Ao comparar os valores de macronutrientes das preparações obtidos por meio da análise direta e indireta, percebe-se que os valores de carboidratos do presente estudo foram maiores na primeira, em três das quatro amostras avaliadas (cuscuz, arroz e torta de abóbora com pescado), enquanto que os resultadosde proteínas e lipídeos foram maiores em todas as preparações, por meio da análise indireta. Silva et al.[25]também encontraram uma grande variação de carboidratos, quando compararam os resultados da análise direta e indireta de 16 pratos tradicionais do Estado de Goiás.

Os valores de proteínas e lipídeos provavelmente diferiram devido ao tipo de pescado utilizado para a análise indireta que é distinto daquele usado para a análise direta, já que a mesma espécie não se encontrava nas tabelas de composição de alimentos. Deve-se levar em consideração que a quantidade de lipídeos e proteínas do pescado varia entre as espécies, sendo a fração lipídica a que mais difere e a proteína varia entre 15 e $25 \%\left[{ }^{[6]}\right.$.

Outros autores também relatam que as TCA possuem diversos erros, tais como a falta de exatidão na identificação, descrição e padronização dos alimentos, assim como no modo de preparo das receitas, além do que nem todas as tabelas possuem a totalidade dos ingredientes ${ }^{[38,40]}$.

Com relação ao valor energético, os resultados obtidos pela análise indireta foram maiores que aqueles por meio da análise direta, com exceção da preparação de cuscuz com pescado, em que o valor energético da análise indireta foi menor que aquele da análise direta. A receita de arroz com pescado também foi menor apenas pela adoção da tabela IBGE[24] quando comparada a análise direta. Vários autores também encontraram valor energético maior nas TCA em comparação àqueles da análise direta $25,38,40]$.

Diante disso, é importante destacar que as variações de valores contidos nas tabelas de composição de alimentos representam significativo risco para indivíduos que possuem alguma patologia e necessitam de um máximo controle na ingestão de nutrientes, visto que pequena variação no conteúdo nutricional pode determinar melhora ou piora do estado nutricional e na qualidade de vida do paciente[40].

\section{CONCLUSÃO}

As preparações desenvolvidas neste estudo além de utilizarem a CMS de pescado, que conferiu alto teor proteicoàs formulações, também utilizou do aproveitamento integral de alimentos como um diferencial, de modo a enriquecer a qualidade nutricional das preparações com os nutrientes concentrados nas cascas e talos de vegetais e de contribuir para a redução do desperdício de alimentos. Embora a maioria das preparações realizadas não atingisse o valorenergético e proteico preconizado pelo PNAE para escolas de tempo parcial, ainda é possível complementar a refeição com a oferta de frutas e/ou bebidas naturais, de modo a atingir o valor energético mínimo definido pela legislação. Com isso torna-se possível sua viabilidade de inserção na alimentação escolar.

Um ponto a ser destacado é que grande parte dos ingredientes vegetais que integraram as preparações desenvolvidas foram utilizados de maneira integral, sem o desprezo de suas cascas e talos, o que diminuiu de certa maneira a aproximação real entre a análise indireta e a direta da composição centesimal, visto que na maioria das tabelas de 
composição de alimentos utilizadas, não há informações nutricionais de tais vegetais, mas apenas da polpa.

O custo das preparações desenvolvidas foram superiores aos valores disponibilizados pelo FNDE. No entanto, a utilização de CMS de pescado juntamente com $\mathrm{O}$ aproveitamento integral de alimentos é uma opção vantajosa para a alimentação escolar, notadamente no tocante ao aumento da qualidade nutricional das preparações e redução de resíduos.

A CMS de pescado é uma forma viável para inserir o pescado na alimentação escolar, dado que é uma fonte de proteína animal saudável, de baixo custo, prática e versátil que pode contribuir para o enriquecimento nutricional e maior aporte proteico das preparações servidas na alimentação escolar, bem como passível de ser adquirida diretamente dos agricultores familiares.

Este estudo contribui na medida que pode ser utilizado como ferramenta pedagógica para os profissionais que trabalham na alimentação escolar de modo a garantir que a oferta de macronutrientes exigida pela legislação do Programa Nacional de Alimentação Escolar seja atendida.

\section{REFERÊNCIAS}

[1] Agência Nacional de Águas - ANA. Quantidade de Água [Internet]. Brasília; 2018 [acesso em 27 abr 2018]. Disponível em: http://www3.ana.gov.br/portal/ANA/aguas-no-brasil/panoramadas-aguas/quantidade-da-agua.

[2] Navarro FKSP, Navarro RD. importância das cores no crescimento, bem-estar e reprodução de peixes. Arq. Ciênc. Vet. Zool. 2017;20(1):45-48.

[3] Instituto Brasileiro de Geografia e Estatística - IBGE. Produção da pecuária municipal. Rio de Janeiro: IBGE; 2016.

[4] Brasil. Produção de peixes no Brasil cresce com apoio de pesquisas da Embrapa [Internet]. Brasília; 2017 [acesso em 13 mar 2018]. Disponível em: https://bit.ly/2lh3jUI

[5] Ogawa M, Maia EL. Manual de pesca. São Paulo: Livraria Varela; 1999.

[6] Sartori AGO, Amancio RD. Pescado: importância nutricional e consumo no Brasil. Segur. Aliment. Nutr. 2012;19(2):83-93.
[7] Dias LPP, Martins ICVS, Cordeiro KS, Nunes JDC. Ácidos graxos essenciais ômega-3 e ômega-6 no leite materno e sua associação com o desenvolvimento infantil: revisão de literatura. Femina.2014;42(5):225-228.

[8] Brasil. Ministério da Educação. Fundo Nacional de Desenvolvimento da Educação - FNDE. Nota técnica no 004/2013: inclusão de pescado na alimentação escolar. Brasília. 11 jul 2013.

[9] Brasil. Resolução no 26, de 17 de junho de 2013. Dispõe sobre o atendimento da alimentação escolar aos alunos da educação básica no Programa Nacional de Alimentação Escolar - PNAE. Diário Oficial da União. 17 jun 2013.

[10] Brasil. Lei no 11.326, de 24 de julho de 2006. Estabelece as diretrizes para a formulação da Política Nacional da agricultura familiar e empreendimentos familiares rurais. Diário Oficial da União. 24 jul 2006.

[11] Veit JC, Freitas MB, Reis ES, Moore ODQ, Finkler JK, Boscolo WRet al. Desenvolvimento e caracterização de bolos de chocolate e de cenoura com filé de tilápia do Nilo (oreochromisniloticus). Alim. Nutr. 2012;23(3):427-433.

[12] Neiva CRP. Aplicação da tecnologia de carne mecanicamente separada - CMS na indústria de pescado. In: Anais do II Simpósio de controle de pescado [Internet]; 2006; São Vicente.São Vicente: SINCOPE; 2006 [acesso em 24 jun 2017]. Disponível em: $\mathrm{ftp} / / / \mathrm{ftp}$. sp.gov.br/ftppesca/IIsimcope/palestra_cristiane_neiva.p $\mathrm{df}$

[13] Vitorassi DC. Desenvolvimento de quibe de carne mecanicamente separada de tilápia com adição de linhaça (linumusitatissimum l.) para inserção na merenda escolar [monografia]. Medianeira: Universidade Tecnológica Federal do Paraná; 2012.

[14] Dallabona BR. Desenvolvimento e estabilidade de linguiça de pescado elaborada a partir de resíduo de filetagem de tilápia do Nilo [dissertação]. São José dos Pinhais:Pontífica Universidade Católica do Paraná; 2011.

[15] Goes ESR, Feiden A, Veit JC, Finkler JK, Goes MD, Boscolo WR. Elaboração de biscoitos tipo cookies com inclusão de peixe. Rev. Agr. 2017;10(36):245-253.

[16] Steuer IRW, Miranda MJL, Aguiar WJ, El-Deir SG. O aproveitamento integral de hortaliças como estratégia de educação para a sustentabilidade nas comunidades do semiárido pernambucano. In: XIII Jornada de Ensino, Pesquisa e Extensão JEPEX; 2013; Recife. Recife: Universidade Federal Rural de Pernambuco; 2013.

[17] Vieira LS, Vieira CR, Faria T, Azeredo EMC. Aproveitamento integral de alimentos: desenvolvimento de bolos de banana destinados à alimentação escolar. Rev. Univ. Vale do Rio Verde. 2013;11(1):185-194. 
Desenvolvimento de preparações para a alimentação escolar. Luz et al.

[18] Casagrande C. Aproveitamento integral de alimentos em uma creche do município de Criciúma - Santa Catarina [monografia]. Criciúma:Universidade do Extremo Sul Catarinense; 2009.

[19] Association of Official Analytical Chemists (AOAC). Official methods of analysis of AOAC International. 17ed. Gaitheersburg: AOAC; 2000.

[20] Kamer JHV de, Ginkel LV. Rapid determination of crude fiber in cereais. Cereal Chemistry. 1952:29(4):239-251.

[21] Brasil. Ministério da Saúde. Agência Nacional de Vigilância Sanitária. Rotulagem nutricional obrigatória: manual de orientação às indústrias de alimentos. 2 versão. Brasilia: Ministério da Saúde; 2005.

[22] Franco G. Tabela de composição química dos alimentos. 9 ed. São Paulo: Editora Atheneu; 2007.

[23] Núcleo de Estudos e Pesquisa em Alimentação - NEPA. Tabela brasileira de composição dos alimentos - TACO. 4 ed. Campinas:NEPA-UNICAMP; 2011.

[24] Instituto Brasileiro de Geografia e Estatística - IBGE. Pesquisa de orçamentos familiares 2008-2009: tabela de composição nutricional dos alimentos consumidos no Brasil. Rio de Janeiro: IBGE; 2011.

[25] Silva MR, Silva MS, Silva PRM, Oliveira AG, Amador ACC, Naves MMV. Composição em nutrientes e valor energético de pratos tradicionais de Goiás, Brasil. Ciênc. Tecnol. Aliment. 2003;23:140-145.

[26] Brasil. Resolução no 1, de 08 de fevereiro de 2017. Altera o valor per capita para oferta da alimentação escolar do Programa Nacional de Alimentação Escolar - PNAE. Diário Oficial da União. 09 fev 2017.

[27] Belik W, Chaim NA. O Programa Nacional de Alimentação Escolar e a gestão municipal: eficiência administrativa, controle social e desenvolvimento local. Rev. Nutr. 2009;22(5):595-607.

[28] Bezerra JAB. Alimentação e escola: significados e implicações curriculares da merenda escolar. Rev. Bras. Educ. 2009;14(40):103115.

[29] Mascarenhas JMO, Santos JC. Avaliação da composição nutricional dos cardápios e custos da alimentação escolar da rede municipal de Conceição do Jacuípe/BA. Sitien. 2006;35:75-90.

[30] Pedraza DF, Melo NLS, Araujo EMN, Silva FA. O Programa Nacional de Alimentação Escolar em escolas públicas municipais. Rev. Bras. Promoç. Saúde. 2017;30(2):161-169.

[31] Cruz LD, Santos AJAO, Santos AAO, Gomes ABL, Andrade FAM, Marcellini OS. Análise de aceitação da alimentação escolar dos alunos das escolas municipais urbanas de Itabaiana - SE. Scient. Plena. 2013;9(10):1-6.
[32] Storck CR, Nunes GL, Oliveira BB, Basso C. Folhas, talos, cascas e sementes de vegetais: composição nutricional, aproveitamento na alimentação e análise sensorial de preparações. Ciênc. Rur. 2013;43(3):537-543.

[33] Rebouças MC, Rodrigues MCP, Castro RJS, Vieira JMM. Caracterização do concentrado proteico de peixe obtido a partir dos resíduos da filetagem de tilápia do Nilo. Sem. Ciênc. Agr. 2012;33(2):697-704.

[34] Avelar JG. Qualidade do patê da carne de matrinxã (Bryconamaz̧onicus, Spixe Agassiz̧, 1829) e sua caracterização financeira [dissertação]. Manaus: Universidade Federal do Amazonas; 2013.

[35] Souza PDJ, Novello D, Almeida JM, Quintiliano DA. Análise sensorial e nutricional de torta salgada elaborada através do aproveitamento alternativo de talos e cascas de hortaliças. Alim. Nutr. 2007;18(1):55-60.

[36] Gondim JAM, Moura MFV, Dantas AS, Medeiros RLS, Santos KM. Composição centesimal e de minerais em cascas de frutas. Ciênc. Tecn. Aliment. 2005;25(4):825-827.

[37] Santos PCP, Nespolo CR, Oliveira FA, Veríssimo CM, Bortolini ACM. Análise direta e indireta de nutrientes e valor energético de pratos salgados tradicionais do Sul do Brasil. Cient. Ciênc. Biol. Saúde. 2011;13(1):45-54.

[38] Santos PCP, Nespolo CR, Oliveira FA, Veríssimo CM, Vivan BD. Composição centesimal e valor energético de pratos tradicionais do Rio Grande do Sul. Braz. J. FoodTechnol. 2009;2:57-64

[39] Pacheco M. Tabela de equivalentes, medidas caseiras e composição química dos alimentos. 4 ed. Rio de Janeiro: Editora Rubio; 2011.

[40] Ribeiro P, Morais TB, Colugnati FAB, Sigulem DM. Tabelas de composição química de alimentos: análise comparativa com resultados laboratoriais. Rev. Saúde Públ. 2003;37(2):216-225. 